\title{
Erratum to: A Novel Nonlinear Link Element for Direct Second-Order Analysis of Trusses Assembled by Weak Shear Stiffness Members
}

Ruijie Zhu ${ }^{\odot a}$, Feng Li ${ }^{\odot a}$, Zhiqin Zhao ${ }^{a}$, and Xingzhong Wang

${ }^{a}$ College of Field Engineering, Army Engineering University of PLA, Nanjing 210007, China

Erratum to: KSCE Journal of Civil Engineering (2020) 24(11):3320-3329

$10.1007 / \mathrm{s} 12205-020-1688-4$

This erratum is published to notify a correction in the title of the article. See the corrected version below:

Errata:

The original version of this article:

A Novel Nonlinear Link Element for Direct Second-Order Analysis of Trusses Assembled by Weak Shear

Was altered as:

A Novel Nonlinear Link Element for Direct Second-Order Analysis of Trusses Assembled by Weak Shear Stiffness Members 